\title{
Reforma do ensino médio uma perspectiva de educação integral.
}

(High school reform a holistic education perspective.)

\author{
Maria dos anjos de Miranda \\ Escola Estadual Professor Djalma Guilherme da Silva/MT-Brasil. \\ Marta Elizete Buchelt Rech \\ Escola Municipal de Educação Básica Lizamara A. de Oliva Almeida/MT-Brasil.
}

Fecha recepción: 01-04-2018

Páginas 121-130

Fecha aceptación: 30-06-2018

\section{Resumo.}

O estudo buscou como objetivo geral, analisar a Medida Provisória nº 746/2016 e as implementações relativas à reforma curricular do ensino médio. Para melhor entendimento sobre o currículo e suas dimensões a (matriz curricular) no âmbito da formação de profissionais, estrutura, qualificação e oferta, assim como, a inserção social e interesses políticos ideológicos. A pesquisa qualitativa fundamentou-se num estudo bibliográfico e documental do MEC, desde a análise à luz conceito de Estado ampliado e teoria ampliada do Estado em Gramsci a gênese do Estado reside, portanto, na divisão da sociedade em classes. Sua principal função conservar e reproduzir esta divisão, garantindo os interesses da classe que domina as outras. Além disso, estudiosos como Frigotto, Neves, Freire entre outros, afirmam que a partir do tensionamento entre sociedade política (organização política de uma sociedade) e sociedade civil (conjunto de organizações e instituições cívicas de uma sociedade), que as transformações são realizadas.

Palavras chave: leis; ideologia; formação; ensino médio; reforma

\section{Abstract.}

The study sought as a general objective, to analyze Provisional Measure $n^{0} 746 / 2016$ and the implementations related to the curricular reform of secondary education. For a better understanding of the curriculum and its dimensions (curriculum matrix) within the scope of professional training, structure, qualification and offer, as well as social insertion and ideological political interests. The qualitative research was based on a bibliographic and documentary study of the MEC, from the analysis to the light concept of extended state and extended theory of the State in Gramsci the genesis of the State resides therefore in the division of society into classes. Its main function is to preserve and reproduce this division, guaranteeing the interests of the class that dominates the others. In addition, scholars such as Frigotto, Neves, Freire, among others, affirm that from the tension between political society (political organization of a society) and civil society (set of organizations and civic institutions of a society), that transformations are carried out

Keywords: laws; ideology; formation; high school; reform 


\section{1.-Introdução.}

Ao longo dos anos foram muitas as reformas do Ensino numa perspectiva de melhoria na qualidade e acompanhar as mudanças que atenda exigências da educação atual, dinâmica e transformadora. Considerando esse cenário, o estudo da Reforma se embasará em discussão bibliográfica e análise documental, com estudiosos como Gramsci, Frigotto, Neves, Freire entre outros.

A Reforma do Ensino Médio Publicada no Diário Oficial da União a Lei 13.415 de 16 de fevereiro de 2017, que altera a Lei de Diretrizes e Bases da Educação e outras leis da área da educação, como formação, oferecimento e estrutura. O currículo fica dividido em partes em cinco itinerários em que o estudante terá de escolher o que 0 sistema ofertar, e as únicas disciplinas obrigatórias serão Língua Portuguesa e Matemática e será ofertada uma língua estrangeira e neste caso a língua inglesa, pois os concursos públicos para ingresso de professores de outras línguas não representa diferença no contexto.

O ensino de história, geografia e artes vão depender do currículo ofertado pela instituição e seus objetivos de formação, as outras disciplinas como filosofia, sociologia não constam mais como disciplinas obrigatórias seus conteúdos serão diluídos nas outras disciplinas e também não há exigências de professor formado em licenciatura, pois pessoas que possuem "notório saber" título capaz de atestar conhecimento adquirido fora do ensino formal estarão qualificadas para exercer 0 ato de ensinar no novo Ensino Médio. As instituições públicas e privadas poderão ofertar o ensino na formação técnica e profissional ou as públicas em convenio com outras instituições.

Art. 36. O currículo do ensino médio será composto pela Base Nacional Comum Curricular e por itinerários formativos específicos, a serem definidos pelos sistemas de ensino, com ênfase nas seguintes áreas de conhecimento ou de atuação profissional: I. linguagens; II. Matemática; III. Ciências da natureza; IV. Ciências humanas; e V. Formação técnica e profissional. $10^{\circ}$ Os sistemas de ensino poderão compor os seus currículos com base em mais de uma área prevista nos incisos I a V do caput. $3 .^{\circ}$ A organização das áreas de que trata 0 caput e das respectivas competências, habilidades e expectativas de aprendizagem, definidas na Base Nacional Comum Curricular, será feita de acordo com critérios estabelecidos em cada sistema de ensino (2017).

Tendo em vista os aspectos apresentados o problema: Será que a reforma do ensino médio veio para diminuir as desigualdades, ou a mesma não passa de uma maquiagem para servir aos interesses governamentais?

Neste artigo pretendeu-se como objetivo geral: Analisar a reforma do ensino médio para além da medida provisória MP $n^{0} 746$, em nome da educação integral, fragmentação e da flexibilização de conteúdo. 
Os objetivos específicos buscaram: 1). Verificar como a reforma está sendo pensada principalmente para as escolas públicas estaduais, onde falta estrutura, qualificação profissional, acesso e permanência destes estudantes. 2). Identificar as políticas públicas e estratégias utilizadas para a qualificação e para a infraestrutura e um plano de redução das desigualdades. 3). Especificar a presença do empresariado nas questões educacionais e a maneira pela qual estão costurando parcerias em busca de formação de mão de obra.

Além disso, se o estudante comprovar que fez um curso a distância e comprovar alguns saberem práticos, não precisa cursar as disciplinas a fins, assim esvaziando ainda mais os saberes necessários a uma boa formação capaz de prepara-lo para um curso universitário de qualidade, onde as exigências são maiores. Um dos objetivos do Ensino Médio, considerando o final de uma etapa fundamental na escolaridade e formação de jovens capazes de analisar criticamente o seu cotidiano e ser autônomos e produtivos.

\section{2.-A conjuntura da reforma.}

$\mathrm{Na}$ atual situação social e política, pesquisas mostram que os jovens entre 18 e 24 anos objetivam ter emprego e renda e supõe se que 0 ensino médio integral e profissionalizante seja capaz de assegurar ferramentas culturais, tecnológicas que desenvolvam habilidades e competências para 0 aperfeiçoamento do raciocínio lógico e comunicativo neste contexto.

Segundo Frigotto para a efetiva universalização democrática da educação básica não bastaria à democratização do acesso, mas há necessidade de se qualificar as condições e objetivas de vida das famílias e das pessoas e aparelhar o sistema educacional com infraestrutura de laboratórios, professores qualificados, com salários dignos, trabalhando numa única escola etc. (Frigotto, 2010, p. 36).

Neste processo, de reforma do ensino considerou-se todas as mudanças desde a Lei de Diretrizes e Bases (1996) nos investimentos oriundos o (Fundo de Manutenção e Desenvolvimento da Educação Básica e, de Valorização dos Profissionais da Educação), as metas estabelecidas no Plano Nacional da Educação, as condições oferecidas para 0 trabalho docente e permanência do aluno na escola, não possibilitam as melhorias desejadas e necessárias. Segundo o Instituto Nacional de Estudos e Pesquisas Educacionais Anísio Teixeira (Inep) o Plano Nacional de Educação PNE, nenhuma meta foi cumprida integralmente, com a redução de investimentos e não priorização da educação, avanços acabam não acontecendo.

Outro fator importante e que reflete diretamente na qualidade é a qualificação e valorização do profissional da educação, a infraestrutura adequada para evolução do aprendizado são inerentes para melhoria. Conforme os indicadores do Índice de Desenvolvimento da Educação Básica (IDEB) revelam que $1 / 4$ dos alunos matriculados no ensino médio chegam a esta fase sem o devido aproveitamento, ou seja, mais de 2.000 milhões de jovens chegam à escola e, não tiram 0 mínimo 
definido dos estudos. Por considerar que o Estado brasileiro inclui organizações com interesses ideológicos, políticos e comerciais, e 0 ensino faz parte da massa de manobra de acordo com objetivos traçados por grupos de políticos, Gramsci nos traz uma reflexão.

Gramsci (1978) da revolução permanente é elaborada e superada na ciência política pela fórmula da "hegemonia civil". Verifica-se na arte política aquilo que ocorre na arte militar: a guerra de movimento transforma-se cada vez mais em guerra de posição, podendo-se dizer que um Estado vence uma guerra quando a prepara minuciosa e tecnicamente em tempos de paz (p. 92). Ainda, que quem vence a guerra é quem está mais bem preparado. Portanto seria necessárias discussões com escolas, intelectuais do meio educacional, a sociedades civil organizada, no entanto, não participaram do processo, visto que serão diretamente impactados. Contudo, de forma efetiva dos grupos aliados e da medida provisória.

O projeto do Ensino Médio foi pautado como opção de melhoria de qualidade, pode se resumir numa proposta curricular, no entanto, faz-se necessário a correspondente qualificação dos quadros docentes e a materialização das condições de trabalho capazes de articular ciência e cultura. Dialogar com o Ensino Fundamental, fase preparatória objetivando o ingresso no Ensino Médio mas, também relevante para 0 ensino aprendizagem. As propostas não avançam por falta de vontade decisiva política e recursos do Governo Federal e resistência ativa de grande parte dos governos estaduais, responsáveis pela política de ensino médio, quanto uma acomodação das instituições educacionais e da sociedade em geral (Frigotto, 2010, p.34).

Faria (2017) coloca que mudanças são necessárias, ao logo de vários séculos, o progresso evolutivo da humanidade ocorreu através de mudanças, mas, nessa perspectiva de ensino integrado e integral, surgem alguns perigos em relação à universalização do Ensino Médio, as condições de acesso e permanência não são iguais para todos, pois nessa idade os alunos da classe menos privilegiada já trabalham para prover seu sustento ou auxiliar na renda familiar. Com isso continua a reproduzir uma dualidade, sutil, mas de uma escola marcada pela diferença na qualidade de ensino, uma para ricos e outra para pobres.

Dentre os inúmeros motivos que levaram a Reforma do Ensino (2016) temos as justificativas do Ministro da Educação, com argumentação de que em outros países 0 Ensino Médio diferenciado e flexibilizado atende as necessidades do desenvolvimento destes países. A proposta solucionaria o problema da qualidade e mão de obra qualificada para o trabalho, já que é profissionalizante. No entanto na Finlândia, por exemplo, os alunos entram tarde no ensino fundamental, aos 7 anos. A educação é obrigatória até os 16 anos de idade. No ensino médio, há uma divisão: 0 aluno pode ir para o sistema vocacionado (técnico, prepara o estudante para uma carreira) ou para o sistema acadêmico, voltado para a universidade. 
PISA (2015) descreve sobre um país que se destaca pela igualdade na educação, qualificação de seus professores e por repensar constantemente o currículo escolar. Com foco na produção de conteúdos pelos seus alunos, e mais contato com a realidade profissional do mercado de trabalho, através de projetos e resolução de problemas. O professor atua como mediador e com muita tecnologia e capacitação, valorização docente, as aulas são de 45 minutos e 15 de intervalo de cada aula, das 08h30min às $15 \mathrm{~h} 00 \mathrm{~min}$ ou $16 \mathrm{~h} 00 \mathrm{~min}$ horas, e em algumas salas com dois professores. Sem contar que é cobrado mais responsabilidades dos alunos, e os pais não levam os filhos para escola, eles vão de ônibus de metro ou de trem.

Ainda, na Finlândia, praticamente não escolas privadas por não precisar pagar mensalidade, relata Helmilnter cambista finlandesa no Brasil. Além disso, valoriza 0 aprendizado de línguas, por isso uma educação bilíngue. Pelas observações do exposto existem alguns princípios básicos na educação, todas as escolas têm a mesma igualdade na qualidade de ensino, não existe escola de elite. Todas as matérias são igualmente importantes, a formação ou status dos pais, são informações que os professores não precisam saber para ensinar, ou seja, só se for estritamente necessário os professores obtêm essa informação, quanto aos alunos não são classificados em melhores ou piores, todos são integrados, procuram incluir inclusive os com deficiência.

Não há professores favoritos, todos são tratados como igual consideração e respeito, no exercício de sua docência, os direitos entre adultos e crianças são levados a sério, respeito mútuo com direitos e deveres, sendo que os professores são contratados por um ano com direito a renovação, ensino de qualidade e gratuito. Ainda são respeitadas a individualidade de cada aluno na aprendizagem, apoio aos que necessitam, e educação corretiva aos que carecem. Ainda convém lembram, que educação prática, confiança, voluntarismo, independência fazem parte do currículo escolar.

Tendo em vista os aspectos observados, fatos históricos, sociais e culturais, não tem parâmetros para comparação, na qualidade da educação desses países citados por membros do governo ligados a educação, para justificar a falta de estrutura, investimento dos governos, valorização profissional e desenvolvimento. Sobretudo, no baixo rendimento nas avaliações externas, menos ainda com a 0 ensino finlandês.

O Ministério da Educação e Cultura aponta para o IDEB, o qual se encontra estagnado desde 2011, os resultados dos últimos dez anos, crescemos apenas 0,3 . [...] O ensino médio, que hoje tem um modelo único no Brasil, forma o jovem exclusivamente para a entrada na universidade. [...] $\mathrm{E}$ apenas $16 \%, 17 \%$ dos jovens hoje acabam ingressando na universidade. [...] O Brasil, comparado com outros países do mundo, tem $8,4 \%$ de matrículas apenas em ensino técnico, enquanto outros países, como a Itália, por exemplo, têm 56\%; a Alemanha, 47\%; a China, 44\%; o Reino Unido, 42\%. (Rossieli Soares da Silva) O Brasil é o único País do mundo que tem o ensino médio único, igual para todos, com um currículo obrigatório 
de no mínimo 13 disciplinas, podendo chegar a até 18 disciplinas. Brasil Medida Provisória nº. 746 de 22 de setembro de 2016.

Há evidente corroboração nas proposições das audiências públicas provenientes de pessoas ou organizações com maior ligação ao governo de Michel Temer.

Percebe se que os vínculos do governo com outros órgãos do setor privado, demonstraram convergência de forças que privilegiaram 0 atendimento dos interesses de grupos, beneficiando os em detrimento de outros. Os discursos foram caracterizados em um movimento ao quais os argumentos instituíram posições.

Neste sentido, Neves (2005) coloca por negar o conflito de classes e até mesmo a existência dessa divisão nas sociedades ditas pós-tradicionais, ancorando uma sociabilidade com base na democracia formal, ou seja, na conciliação de interesses de grupos plurais, na alternância de poder entre os partidos políticos renovados, na auto-organização e envolvimento das populações com as questões ligadas às suas localidades, no trabalho voluntário e na ideologia da responsabilidade social das empresas [sem tocar] nas relações de exploração.

O contexto ao qual se deu a aprovação da reforma na conjuntura nacional, marcada por interesses políticos que constitui o Brasil, de uma agenda governamental que objetiva entre outras finalidades a retirada de direitos sociais que se destaca pela PEC 55, aprovada, que congela por 20 anos investimentos nas áreas sociais e atinge profundamente a educação, e a facilitação e a adoção da Lei da Terceirização que permite a realização de trabalho por meio do ensino público.

Além disso, interferindo nos Institutos Federais de Educação de ensino médio que segundo as avaliações do ENEM apresenta bons resultados. As políticas públicas de formação de professores desvalorizam a profissionalização docente, à medida que permite pessoas de "notório saber", ou seja, sem licenciatura ministrando aulas, para atender demandas especificas do mercado.

Para Faria (2017) as recomendações das Organização das Nações Unidas para a Educação, a Ciência e a Cultura, países com circunstancias socioeconômicas altamente diferenciadas propõem revisão e reestruturação nos currículos para atender finalidades que favoreçam o desenvolvimento. Já no segundo ciclo da educação secundária, os países europeus têm experimentados diversas abordagens de articulação básica geral e educação técnico-profissional e treinamento, que incluem diversificação de currículo, aumento do status da qualificação docente, melhorias no encaminhamento profissional e intermediação com 0 ensino superior. (2008, p.18)

Todavia, em alguns países da Europa já acontecem, entretanto são realidades totalmente diferentes, pois a qualidade de vida, o nível sócio econômico, e os serviços oferecidos a população atendem as necessidades do bem-estar social, politicamente com níveis muito baixos de corrupção, investimento estrutural, 
qualificação profissional. Quanto ao ensino aprendizagem na primeira fase, há manutenção do diálogo em função do ensino de qualidade que prepara para próxima fase. Enquanto no Brasil, as pesquisas revelam baixo aprendizado, e ainda analfabetismo. Em função das reformas e do processo formativo foi criada a Base Nacional Comum Curricular porém, ainda não conseguiram chegar ao um consenso.

Os conteúdos curriculares ou de aprendizagem abarcarão competências essenciais e outras, opcionais, em função de necessidades especificas da coletividade. Competências essenciais tais como o letramento e a numeração serão reforçados, desenvolvidas e complementadas com a responsabilidade cívica e a cidadania. Segundo definição do Ministério da Educação Base Nacional Comum Curricular é um documento de caráter normativo que norteia os currículos e os propósitos didáticos da educação infantil ao ensino médio, estabelecendo conhecimentos e competências e habilidades para desenvolvimento do estudante, para formação integral, justa democrática e inclusiva.

\section{3.-Metodologia.}

O texto elencou a reforma do ensino médio considerando a Medida Provisória (MP) no 746/2016 e as implementações relativas à reforma curricular do ensino médio. Parte do entendimento do currículo em suas dimensões restritas (matriz curricular) e seu âmbito de formação dos profissionais, estrutura, qualificação e oferecimento. Assim como inserção social e interesses políticos ideológicos.

Deste modo, 0 estudo fundamentou-se numa pesquisa documental, bibliográfica e documentos do MEC, analisou-se as possibilidades de investimentos, acesso desses jovens ao ensino médio. Para Alvarenga (2013) a pesquisa documental se busca informações em informativos, registros e ou acontecimentos ocorridos recentemente ou no passado, no entanto som fontes originais de informação [...] a bibliográfica se baseia numa concepção já escrita a qual pode-se realizar outra análise.

O estudo analisou a proposta da Reforma que buscou verificar condições oferecidas se estas possibilitam a qualidade desejada na aprendizagem e as mudanças no Ensino e se há influências sobre o processo com a definição política. Todavia, se aborda neste o conceito de Estado ampliado, pois na teoria Ampliada do Estado em Gramsci a gênese do Estado reside, portanto, na divisão da sociedade em classes, sendo sua principal função conservar e reproduzir esta divisão, garantindo os interesses da classe que domina as outras.

\section{4.-Discussão dos Resultados.}

A discussão dos resultados se fez numa síntese dos documentos e leis pesquisadas, bem como, numa síntese, nas vozes dos autores expertos destacados (Frigotto, Neves, Freire, Gramsci e Giddens).

Quadro 1: Síntese documental.

\begin{tabular}{l|l} 
Leis & Proposta
\end{tabular}




\begin{tabular}{|c|c|}
\hline $\begin{array}{l}\text { A Reforma do } \\
\text { Ensino Médio Lei } \\
13.415 \text { de } 16 \text { de } \\
\text { fevereiro de } 2017\end{array}$ & $\begin{array}{l}\text { Altera a Lei de Diretrizes e Bases da Educação e outras leis } \\
\text { da área da educação, como formação, oferecimento e } \\
\text { estrutura }\end{array}$ \\
\hline $\begin{array}{c}\text { Medida Provisória } \\
n^{\circ} 746 \text {, de } 2016\end{array}$ & $\begin{array}{l}\text { Reforma do ensino médio/Base Nacional Comum Curricular } \\
\text { e por itinerários formativos específicos, a serem definidos } \\
\text { pelos sistemas de ensino, com ênfase nas seguintes áreas } \\
\text { de conhecimento ou de atuação profissional: I. linguagens; } \\
\text { II. Matemática; III. Ciências da natureza; IV. Ciências } \\
\text { humanas; e V. Formação técnica e profissional. }\end{array}$ \\
\hline $\begin{array}{l}\text { Lei de Diretrizes e } \\
\text { Bases (1996) }\end{array}$ & $\begin{array}{l}\text { A lei que regulamenta o sistema educacional público ou } \\
\text { privado da educação básica ao ensino superior. }\end{array}$ \\
\hline
\end{tabular}

Fonte: a própria pesquisa (2018).

Levando se em conta os aspectos apresentados, concluímos que o problema da qualidade da aprendizagem do ensino brasileiro está na falta de estrutura de escolas/colégios, ou seja, a questão não pode ser apoiada somente na mudança de currículo isso, é desconsiderar as questões socioeconômicas existentes no Brasil. Sendo assim, a educação brasileira continua permeada por diversos problemas: escolas sem estruturas físicas adequadas para 0 atendimento às demandas existentes, desvalorização dos profissionais da educação, falta de investimento financeiro destinado à educação.

Certamente 0 Ensino Médio a muitos anos vem necessitando de uma política clara e objetiva, considerando ainda que o problema também está na base. Contudo, é preciso que ocorra a mudança em todas as etapas do ensino, as decisões acerca da reforma devem ter a participação de toda a comunidade civil organizada, (estudantes, pais, profissionais e pesquisadores da educação, entre outros).

Quadro 2: Síntese a voz dos autores expertos.

\begin{tabular}{|c|l|}
\hline Autor & A concepção \\
\hline $\begin{array}{c}\text { Frigotto } \\
(2010, \\
\text { p.36) }\end{array}$ & $\begin{array}{l}\text { Coloca que para a universalização da aprendizagem de qualidade } \\
\text { seria necessário a democratização, condições de trabalho e renda } \\
\text { das famílias desprivilegiadas e melhorar a infraestrutura das escolas } \\
\text { com bibliotecas, laboratórios e igualdade de acesso e qualificação } \\
\text { docente. }\end{array}$ \\
\hline $\begin{array}{c}\text { Gramsci } \\
(1978, \\
\text { p.92) }\end{array}$ & $\begin{array}{l}\text { A aborda um pensamento reformista e revolucionário numa visão } \\
\text { crítica e histórica nos processos sociais. }\end{array}$ \\
\hline $\begin{array}{c}\text { Freire } \\
(2000)\end{array}$ & $\begin{array}{l}\text { Paulo Freire enfatiza à prática educativa-crítica: "A reflexão crítica } \\
\text { sobre a prática, esta tornou-se uma exigência da relação }\end{array}$ \\
& $\begin{array}{l}\text { Teoria/Prática sem a qual a teoria pode ir virando blábláblá e a } \\
\text { prática, ativismo" [...] "...ensinar não é transferir conhecimento, mas } \\
\text { criar as possibilidades para a sua produção ou a sua construção. }\end{array}$ \\
Baseado no conjunto de sua obra.
\end{tabular}


(2005, na existência de uma sociedade moderna, ancorando uma

p.15) sociabilidade de democracia normal.

Fonte: A própria pesquisa (2018).

Frigotto, (2010, p.27), colocam que no âmbito escolar se cristalizou a persistência de forças conservadoras no manejo do poder de manutenção de seus interesses e a timidez do Governo na direção de um projeto nacional de desenvolvimento popular de massa.

Tendo em vista os aspectos apresentados, na proposta de reforma continua a reproduzir desigualdades, onde o estado não atua, deixando espaços para outras organizações agirem a favor de seus interesses, deixando a preocupação de fazer uma escola de integração, valorizada e universalizada.

\section{5.-Conclusão.}

Neste contexto, coloca-se a política ideológica com uma maquiagem democrática. No entanto, essa diferenciação retira a universalização da aprendizagem a todos enfatizando o caráter excludente aos mais fragilizados socialmente, moradores de periferia entre outros. A educação para ser de qualidade, é necessário um currículo rico, com projeto político pedagógico, ético, que assegure o acesso à ciência, a cultura, capazes de propiciar bases consistentes para a formação do cidadão capaz de exerce sua cidadania plena. Disciplinas como história, filosofia, sociologia, artes e biologia, física são reconhecidas por socializar os saberes universais e colabora para formação do pensamento crítico e social.

Assim sendo, a reforma foi pensada para as escolas públicas estaduais e o que se pode dizer destas, onde falta estrutura, qualificação profissional, acesso e permanência destes estudantes devido à necessidade maior de auxiliar na renda familiar.

No entanto, as políticas públicas deveriam ser estratégias de qualificação e infraestrutura e um plano de redução das desigualdades eficaz, a qual não foram representados nas ações pela medida provisória, com a redução dos recursos do FUNDEB e congelamento por 20 anos de investimentos, pesquisas revelam ser insuficiente para a demanda.

Dessa forma, a presença do empresariado nas questões educacionais os quais estão estabelecendo-se de maneira explicita e implícita costurando parcerias em busca de formação de mão de obra, a escola pública representa um nicho do mercado, não só na formação, mas, também atuando em várias áreas fornecendo matérias didáticos e consultorias. Em consequência disso, vai além dos negócios, fixando ideologias nesses espaços importantes para mundo dos negócios.

Contudo, nesse processo histórico cabe a dinâmico aos que rejeitam a atual situação munir de esforços no sentido de transforma lá, promovendo ações no sentido de 
mudar o pensar e o agir, buscando nichos da educação através da política cultural, ideológica com elevação do nível de informação da massa para uma participação efetiva em busca de construir uma sociedade mais justa através do ensino.

\section{6.-Referências.}

Conselho Nacional de Educação. (2011). Parecer CNE/CEB $n^{0} 5$, de 4 de maio de 2011, trata das Diretrizes Curriculares Nacionais para o Ensino Médio. Brasília: Ministério da Educação.

Congresso Nacional. (2017). A Reforma do Ensino Médio Lei 13.415 de 16 de fevereiro de 2017. Recuperado de: http://www.camara.gov.br/proposicoes.

Conselho Nacional de Educação. (1996). Lei no 9.394, de 20 de dezembro de 1996. Estabelece as diretrizes e bases da educação nacional. Brasília: MEC.

Faria, C. (2017). Organizações das nações Unidas (ONU). São Paulo: Cortez

Freire, P. (2000). Pedagogia da Autonomia: Saberes necessários a prática educativa. 15.ed. São Paulo: Editora Paz e Terra.

Frigotto, G., Ciavatta, M., Ramos, M. (2005). Ensino Médio Integrado: Concepções e contradições. São Paulo: Cortez.

Gramsci, A.(1978). Os intelectuais e a organização da cultura. Tradução de Coutinho. $3^{a}$. ed. Rio de Janeiro: Civilização Brasileira.

Ministério da Educação. (2017). Base Nacional Comum Curricular. Proposta preliminar. Abr. 2016. Recuperado de: http://basenacionalcomum.mec.gov.br.

Programme for International Student Assessment (2015). Overview Recuperado de: https://nces.ed.gov/surveys/pisa.

Neves, L.M.W. (Org.). (2005). A nova pedagogia da hegemonia: estratégias do capital para educar o consenso. São Paulo: Xamã. 